\title{
Phosphorus in Surface Sediments of Bohai Sea And Adjacent Area
}

\author{
Xiang-li LV ${ }^{1, a}$ 、 Hong $\mathrm{HU}^{2, \mathrm{~b}}$ 、 Long-Qiang $\mathrm{Li}^{2, \mathrm{c}}$ \\ ${ }^{1}$ Ocean University of China, Qingdao 266100, China \\ 2 Ocean University of China, Qingdao 266100, China \\ a1034471106@qq.com, ${ }^{\text {b } 1633823217 @ q q . c o m, ~}{ }^{\text {c } 1456557002 @ q q . c o m ~}$
}

Keywords: Bohai Sea and its adjacent areas; Sediments; phosphorus.

\begin{abstract}
We study the content of Phosphorus, spatial distribution, influencing factors and the ecotoxicity in the sediment of the Bohai Sea and its adjacent area (the north Yellow Sea).The results indicate that the content of total phosphorus in the study area ranges from $0.2962 \mathrm{mg} / \mathrm{g}$ to $0.5422 \mathrm{mg} / \mathrm{g}$, and its spatial distribution shows that the content of total phosphorus (P) decreases from the Bohai Sea to its adjacent sea area. The results of the correlation between the total phosphorus with organic carbon and particle size of sediments show that there is a slight correlation between total phosphorus and organic carbon in the study area, the content of total phosphorus is positively correlated with the percentage of particle size in the range of $0.008 \mathrm{~mm}-0.004 \mathrm{~mm}$. The study find that total phosphorus (TP) and organic carbon (TOC) in the sediments of Bohai Sea and its adjacent sea area do not cause toxic effect to the benthic environment.
\end{abstract}

\section{Analytical methods}

The study area is shown in Fig.1. The total phosphorus in sediments was determined by digestion method, and the organic matter in the samples was destroyed by concentrated sulfuric acid under the action of the catalyst. The organic phosphorus and inorganic phosphorus in the samples were in the form of $\mathrm{PO}^{3-}$. In the acidic solution, we droped the indicator, then measured at a wavelength of $420 \mathrm{~nm}$ using a $722 \mathrm{~S}$ spectrophotometer, the error was less than $\pm 5 \%$. The content of organic carbon in the sediments samples of this study was determined by potassium dichromate-oxidation-reduction titration. The particle size of the sediment sample was analyzed using a particle size analyzer.

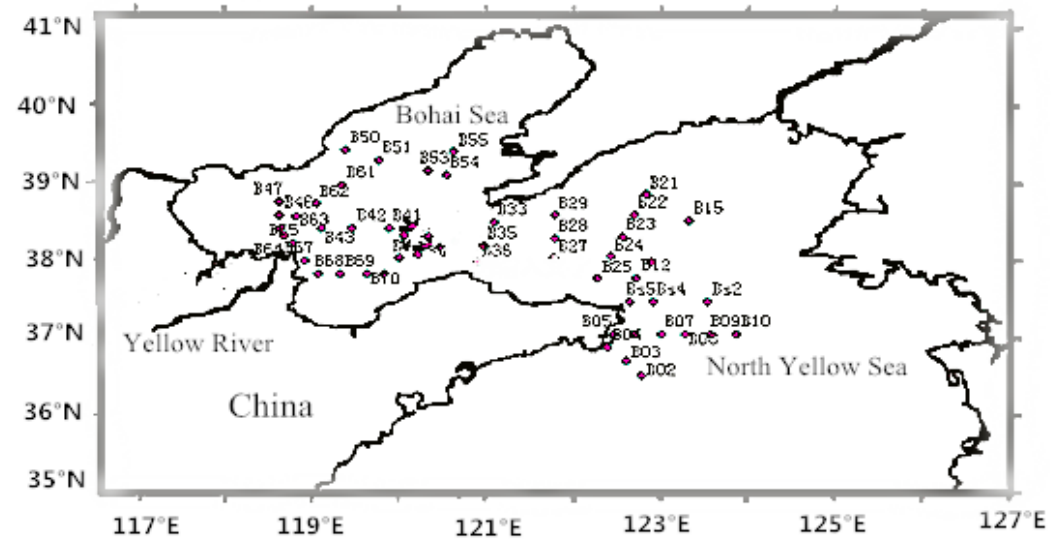

Fig. 1 Stations in the Bohai sea and its adjacent area

\section{Results And Discussion}

\subsection{Content and Distribution Characteristics of Total Phosphorus in Surface Sediments}

It can be seen from Table 1 that the total phosphorus content in the sediments of the Bohai Sea and its adjacent area ranges from $0.2962 \mathrm{mg} / \mathrm{g}$ to $0.5422 \mathrm{mg} / \mathrm{g}$, with an average value of 0.3655 $\mathrm{mg} / \mathrm{g}$. In the Bohai Sea (Fig. 2), the variation of total phosphorus content ranges from $0.2962 \mathrm{mg} / \mathrm{g}$ to $0.5422 \mathrm{mg} / \mathrm{g}$, with an average value of $0.3774 \mathrm{mg} / \mathrm{g}$, and the total phosphorus content in the 
Bohai Sea is higher than its adjacent area. The variation of total phosphorus content ranges from $0.3101 \mathrm{mg} / \mathrm{g}$ to $0.4885 \mathrm{mg} / \mathrm{g}$, with an average value of $0.3553 \mathrm{mg} / \mathrm{g}$ in the adjacent area of the Bohai Sea (North Yellow Sea area). The results of variance analysis shows that there is no significant difference in total phosphorus content between the Bohai Sea and its adjacent area $(\mathrm{F}=9.798, \mathrm{P}=$ 0.237). As shown in Fig. 2, the maximum value of total phosphorus in the sediments of the Bohai Sea appears in the waters near the Yellow River estuary, the total phosphorus content in eastward and northward gradually reduces. The minimum value appears in the middle part of the Bohai Sea. In the adjacent sea area of the Bohai Sea, the maximum concentration of total phosphorus in sediments appeares in the waters near Weihai, while the total phosphorus content in eastward and northward gradually reduces too. The Bohai Sea is a near-enclosed sea, the sea water exchange time is long and affects its self-purification capacity. In addition, under the action of sediment and tidal current, the reason for the high total phosphorus content near the Yellow River estuary of the Bohai Sea is due to the high phosphorus (P) in the Yellow River sediment and the input of phosphorus in the domestic sewage and industrial waste water in the city of Bohai Bay.

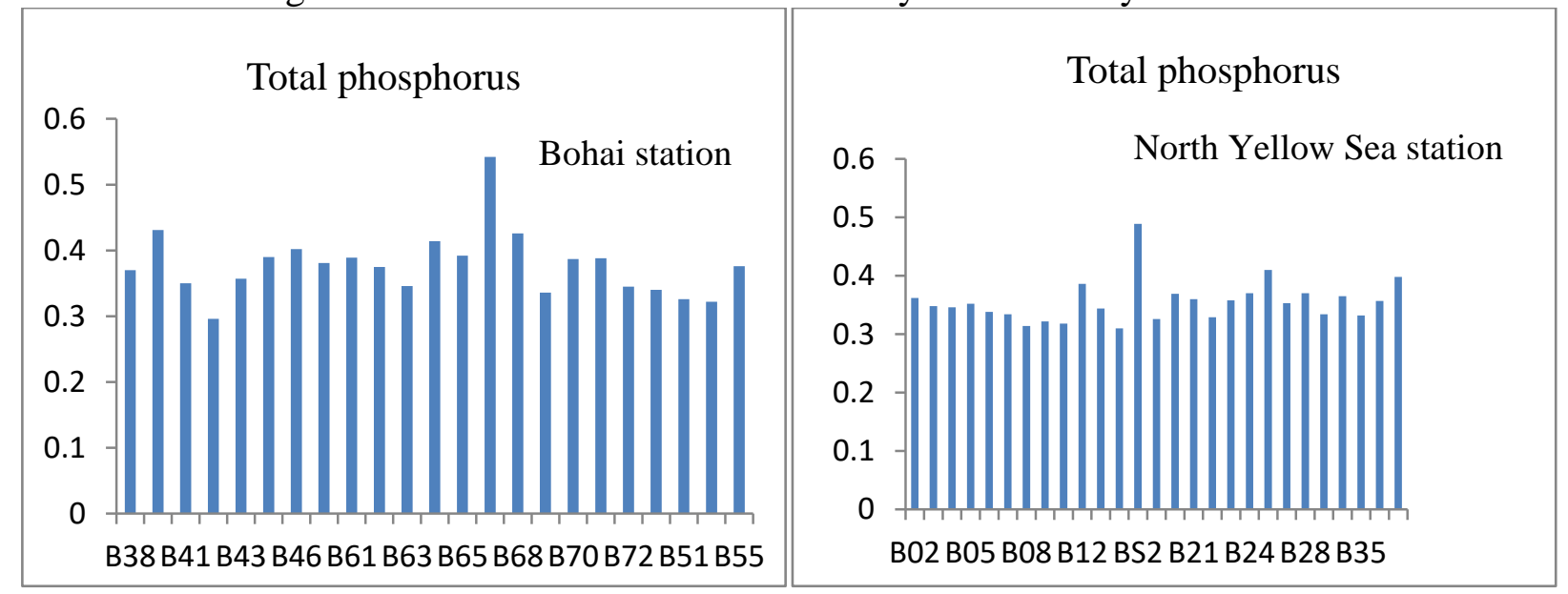

Table 1 The content of total phosphorus in sediments of Bohai sea and adjacent area

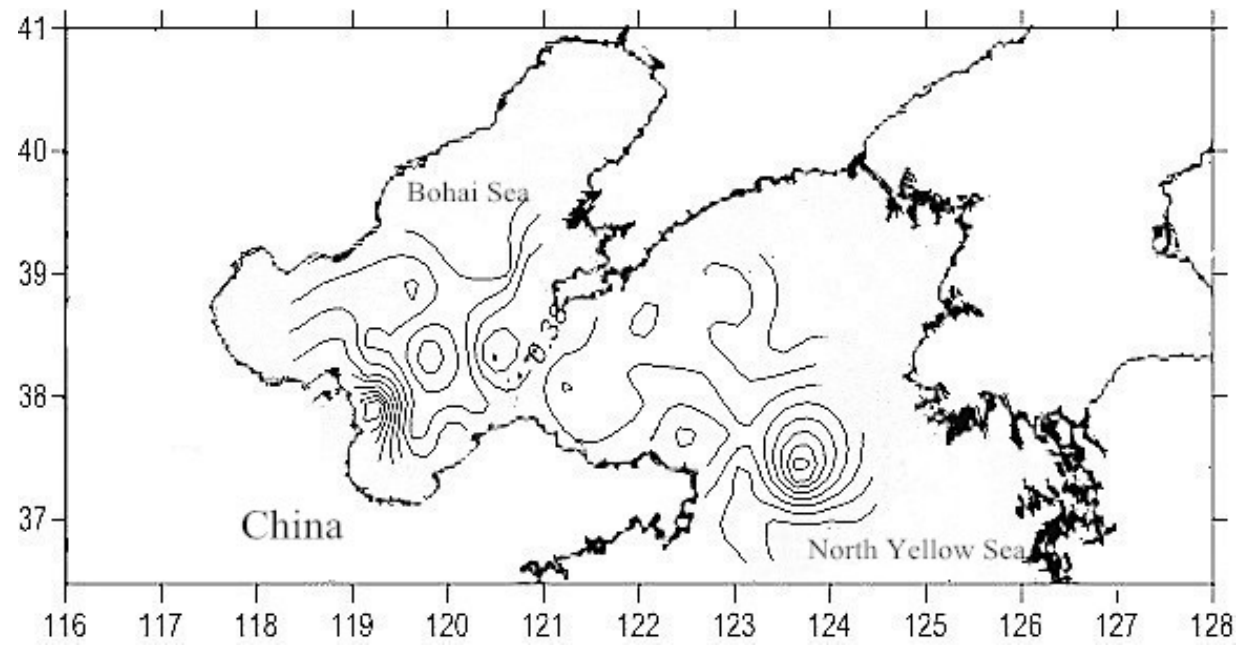

Fig. 2 Distribution of total phosphorus in sediments of Bohai sea and its adjacent area

\subsection{Analysis of Factors Affecting Total Phosphorus Content in Sediments}

\subsubsection{Organic carbon content and its spatial distribution}

The continental margin of the shelf is the most critical area in the study of land-sea interaction and is an important global carbon reservoir, playing an important role in the process of material cycling. The variation of organic carbon content in the sediments of the Bohai Sea and its adjacent area ranges from $0.1883 \%-2.1189 \%$, with an average value of $0.8230 \%$. The range of organic carbon content in the sediments of the Bohai Sea is between $0.3727 \%$ and $1.9660 \%$, with an average of $0.8413 \%$.The range of organic carbon content in the adjacent Bohai Sea (North Yellow 
Sea) is $0.1883 \%-2.1189 \%$, the average is $0.8081 \%$. We analyze the correlation between total phosphorus content and organic carbon content in sediments of the Bohai Sea and adjacent area,it find that there is a positive correlation between the total phosphorus and the organic carbon in the sediments of the Bohai Sea and adjacent area, and the correlation coefficient is 0.0367. Organic carbon in the different sea areas changes greatly, while the total phosphorus content is basically stable, which may indicates that the source of the organic carbon and total phosphorus in the sediments of Bohai Sea and adjacent area (North Yellow Sea region) is different.

\subsubsection{Sediment particle size}

Phosphorus in coastal sediments is mainly derived from river transport. The source of phosphorus in the Bohai Sea and its adjacent area mainly comes terrestrial material. The material composition of sea sediments can reflect the transport characteristics of the land and river (Wang Guizhi et al., 2002). In addition to material sources, the granularity effect is also an important control factor. It is generally believed that the smaller the particle size of the sediments, the larger the specific surface area, the stronger the adsorption capacity and the higher the phosphorus content. The content of phosphorus (P) in the surface sediments of the Bohai Sea and adjacent area has a certain relationship with the sediment size. The correlation analysis of total phosphorus content and the percentage of particle size in different particle size ranges shows that there is a significant positive correlation between the total phosphorus content and the percentage of particle size in the range of $0.008 \mathrm{~mm}-0.004 \mathrm{~mm}(\mathrm{R}=0.332, \mathrm{P}=0.05 *)$, In this range, the larger the particle size, the higher the total phosphorus content.

\subsection{Ecological risk assessment}

Organic carbon (TOC) and total phosphorus (TP) in the sediment to a certain amount will have a certain toxic effect on the marine benthic organisms. The current assessment of organic carbon (TOC) and total phosphorus (TP) ecotoxic effects in sediments is less. In this study, the ecological assessment of the survey area is conducted using the guidelines for quality assessment developed by the Ministry of Environment and Energy of Ontario, Canada [8]. This evaluation guide divides the potential ecological hazards of the source elements into three levels: (1)Class I sediment standards, which have not yet produced toxic effects on aquatic organisms;(2)Class II sediments standards, where sediment has been contaminated, but most benthic organisms can withstand;(3)Class III sediment standards, benthic creatures may suffer significant damage (Table 2).

The results show that the maximum value of total phosphorus in the sediments of the Bohai Sea is $0.0542 \%$ and less than $0.06 \%$, which belongs to the standard of Class $\mathrm{I}$, that is, it is not yet produced toxic effects on aquatic organisms. The maximum value of total phosphorus in the sediments of adjacent Bohai Sea (North Yellow Sea) is $0.0489 \%$ and less than $0.06 \%$, which belongs to the standard of Class I and not produces toxic effects on aquatic organisms. The organic carbon mass fraction in the sediment of Bohai Sea is only $1 \%$ in the vicinity of the Yellow River estuary, which is in the Class II sediment standard and the other stations are in Class I standard. This may be related to the large amount of terrestrial substances carried by the Yellow River. The organic carbon content in the sediments of the adjacent area of the Bohai Sea (North Yellow Sea area) is greater than $1 \%$ in the sea area between Yantai and Dalian, that is in the standard of ClassII, where the sediment is contaminated, but most benthic organisms can tolerate, which may be related to hydrodynamic conditions and terrestrial inputs. The organic carbon mass fraction of the other stations in the northern Yellow Sea is less than 1\%, and the toxic effects have not produced on the aquatic organisms.

Table 2 Hazard evaluation standard of biogenic elements

\begin{tabular}{cccc}
\hline Biogenic Element & Level 1 & Level 2 & Level 3 \\
\hline TOC (\%) & $<1$ & $1-10$ & $>10$ \\
TP (\%) & $<0.06$ & $0.06-0.2$ & $>0.2$
\end{tabular}

There are differences between the Bohai Sea and it adjacent area and the Hudson Bay in Ontario, Canada, in terms of latitude, land and sea location, the nature of marine sediments and the sewerage of coastal cities. 
Therefore, using this standard to evaluate the pollution situation in the Bohai Sea and its adjacent area can reflect the harmful effects of pollutants on marine life, to a certain extent, but we still need to investigate other elements (nitrogen and carbon), analyze and conduct pollution assessment, in order to fully understand the ecological environment of the Bohai Sea and adjacent area, which can also provide the basis for marine environmental protection.

\section{Conclusion}

(1)The content of total phosphorus (TP) in the sediments of the Bohai Sea and its adjacent area ranges from $0.2962 \mathrm{mg} / \mathrm{g}$ to $0.5422 \mathrm{mg} / \mathrm{g}$, with an average value of $0.3655 \mathrm{mg} / \mathrm{g}$. In the study, the total phosphorus (TP) content shows a decreasing trend from the Bohai Sea to its adjacent area, and the maximum content of total phosphorus (TP) appeares in the shallow sea area near the Yellow River estuary.

(2)The content of organic carbon in the sediments of the Bohai Sea and its adjacent area ranges from $0.3727 \%$ to $1.9660 \%$, with an average of $0.8413 \%$. In terms of the correlation between organic carbon content and total phosphorus in sediments, we find a slight positive correlation between organic carbon and total phosphorus, with a correlation coefficient of 0.0367 , this may be related to the different sources of organic carbon and total phosphorus in the study area.The variation of particle size in the sediments of Bohai Sea and adjacent area ranges from $0.004 \mathrm{~mm}$ to $0.172 \mathrm{~mm}$,with an average value of 0.027 $\mathrm{mm}$. The trend of the change of the average particle size is consistent with the spatial trend of the total phosphorus content. The correlation analysis shows that there is a significant positive correlation between the total phosphorus content and the percentage of particles in the range of 0.008 $\mathrm{mm}-0.004 \mathrm{~mm}(\mathrm{R}=0.332, \mathrm{P}=0.05 *)$, and there is no significant correlation with the percentage of particle size in other ranges.

(3) The results of ecological toxicity evaluation show that the organic carbon (TOC) mass fraction in the Bohai Sea sediments is greater than 1\% in the waters of the Yellow River estuary and at the junction of the two seas, organic carbon content in the Sediment of adjacen Bohai Sea (North Yellow Sea area) is more than $1 \%$ between Yantai and Dalian, belonging to the class II sediment standards, which may be related to hydrodynamic conditions and land source input and other factors. In addition to these two individual stations, the mass fraction of organic carbon in the Bohai Sea and adjacent area sediments (North Yellow Sea area) is less than $1 \%$ and belongs to Class I sediment standards. The contents of total phosphorus (TP) in the sediments of the Bohai Sea and adjacent area is less than $0.06 \%$,which belongs to the standard of ClassI. Therefore, the ecological environment of the Bohai Sea and adjacent area is not yet toxic to aquatic organisms, but in recent years, the Bohai red tide phenomenon occurs frequently, so environmental protection is still a top priority work, still need to do further research with other factors.

\section{Acknowledgments}

Thanks to my teacher for his guidance and support, his name is Hu Hong and is the corresponding author. In addition, I also want to thank Li Long-qiang 's help to me. Finally, thanks to all the people who helped me.

\section{References}

[1]Liu Jun, Yu Zhigang, Zang Jiaye etal. Distribution and budget of organic carbon in the Bohai and YellowSeas[J].AdvancesinEarthScience,2015.30(5):564-578,doi:10.11867/j.issn.100-8166.2015.05. 0564 .

[2]Wang Gui-zhi, Gao Shu.Effects of Water Exchange and Suspended Sediment Characteristics on Sedimentation in the Bohai Sea Strait [J]. Ocean Sinica, 2002,21 (1): 43-48.

[3]Kuster-Heins K, Steinmetz E, De Lange G J, et al. Phosphorus cycling in marine sediments from the continental margin off Namibia[J].Marine Geology,2010,274(1-4):95-106.

[4]He Huijun, Yu Zhigang, Yao Qingzhen, et al. Distribution of phosphorus in sediments from the 
Changjiang Estuary and its adjacent sea[J].Acta Oceanologica Sinica,2009,31(5):19- 30.

[5]Du Dewen, Shi Xuefa, Meng Xianwei and so on. (1): 78- 82.Progress of Sediment Geochemistry in the Yellow Sea [J]. Advances in Marine Science, 2003,21 (1): 78- 82.

[6]Yue Wei-zhong, Huang Xiao-ping.Studies on Biogeochemistry of Nitrogen and Phosphorus in Offshore Sediments [J]. Taiwan Strait, 2003,22 (3): 407-414.

[7]Salomons W, Gerritse R G. Some observations on the occurrence of phosphorus in recent sediments from Western Europe[J].Science of the Total Environment,1981,17(1):37-49.

[8]National Ocean Bureau 908 Special Office. Marine Chemical Survey Technical Regulation [M]. Beijing: Ocean Press, 2006. 